\title{
Comparing Slovenian year 8 and year 9 elementary school pupils' knowledge of electrolyte chemistry and their intrinsic motivation
}

\author{
Iztok Devetak $^{a}$, Erna Drofenik Lorber ${ }^{b}$, Mojca Juriševič ${ }^{a}$ and Saša A. Glažar ${ }^{a}$ \\ Received 15th October 2008, Accepted 25th July 2009 \\ DOI: $10.1039 / b 920833 j$
}

This study explored the differences between eight-year elementary school pupils (before the curriculum reform) and nine-year elementary school pupils (soon after the curriculum reform) in Slovenia, as regards specific chemistry knowledge and motivation to learn chemistry. Altogether, 191 elementary school pupils participated in the study. The results show that pupils of nine-year elementary school are not significantly better at chemistry knowledge test scores than eight-year elementary school pupils. Similar results were obtained when comparing intrinsic motivation. The results also show that those students who exhibit a higher level of intrinsic motivation to learn chemistry do not perform better at the test as a whole, but the correlation is low, although statistically significant, between motivation and pupils' performance at solving selected problems presented in this paper. Results show that students develop different misconceptions of selected chemical concepts. Based on the results of this study, some guidelines for teachers are suggested.

Keywords: chemistry knowledge, ITLS model, submicroscopic representations, understanding of chemical concepts, intrinsic motivation, elementary school, school reform

\section{Introduction}

Learning chemistry is a complex process, and combining different levels of chemical concepts (macroscopic, submicroscopic and symbolic ones) is an important part of it. Research (Bradley et al., 1998; Johnson, 1998; Gabel, 1999; Sanger, 2000; Chittleborough et al., 2002; Harrison and Treagust, 2002; Solsona et al., 2003; Papageorgiou and Johnson, 2005; Toth and Kiss, 2006; Stains and Talanquer, 2008; Devetak et al., 2009) shows that the teaching process organised in such a way can contribute to diminishing students' misunderstandings or incomplete comprehensions of chemical concepts, which is still recognised as a great problem all over the world.

Educational strategies in chemistry education should lead to knowledge with understanding, and should include macroscopic, submicroscopic and symbolic levels of chemical concepts. The macroscopic component - concrete or sensory representation of chemical concepts - is represented with experiments. Observations at the macroscopic level are explained by the submicroscopic one (the abstract particulate level). Symbolic levels of chemical concepts (symbols of elements, chemical formulae and equations, mathematical equations, graphical representations such as submicrorepresentations of the particulate nature of matter different models, scheme, etc.) are used by scientifically literate people to communicate easily about the phenomena at the abstract level; this is the most difficult one for students to comprehend, especially if they lack the understanding of the submicroscopic level of chemical concepts. Reasonable

\footnotetext{
${ }^{a}$ University of Ljubljana, Faculty of Education, Kardeljeva ploščad 16,

Ljubljana, Slovenia, e-mail: Iztok.Devetak@pef.uni-lj.si

${ }^{b}$ Primary school Rogatec, Ptujska cesta 30, Rogatec, Slovenia
}

understanding of the phenomena is established when all three levels of concepts overlap one another, supported by visualization elements, in a specific way in students' working memory. These relationships are presented in the Interdependence of the Three Levels of Science Concepts Model (ITLS) (Fig. 1).

The ITLS model draws on different educational theories, such as Paivio's dual coding theory (Paivio, 1986) (two cognitive subsystems, one specialized for processing of nonverbal objects or events, and the other specialized for dealing with language), Mayer's Selecting-OrganizingIntegrating (SOI) model of meaningful learning (Mayer, 1996) (the model representing the processes of Selecting relevant information, Organizing information in a meaningful way, and Integrating the new information with the learner's prior knowledge) and Johnstone's model of information processing (Johnstone et al., 1994) (the model of information entering the learner and how it is processed in the working and long-term memory), cognitive theory of multimedia learning and Mayer's theory of effective illustrations (Mayer, 1993) (both theories build on implementation of simple illustrations to help direct the student's attention to specific elements in building a mental model by which they acquire knowledge and proceed toward meaningful knowledge). For more details on theory descriptions and their implementation in ITLS model see Juriševič et al. (2008) and Devetak et al. (2009). Mayer and Moreno (2001) argued that, in the process of constructing meaningful knowledge for students, teachers should follow the multiple representation principle: presenting the concept in words and pictures together. Learning science is also strongly connected with building knowledge through understanding and concept linking in students' long-term memory by interpreting multi-modal representations of science phenomena (Ainsworth, 1999; Lemke, 2004), and that 


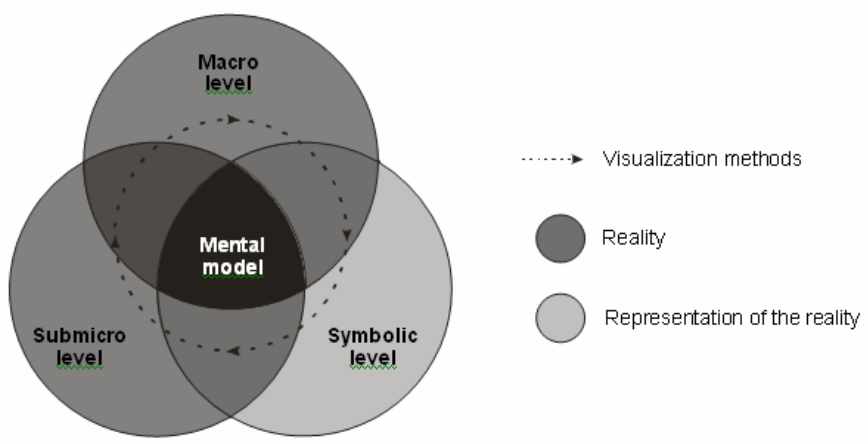

Fig. 1 Model representing Interdependence of Three Levels of Science Concepts - ITLS model (Devetak, 2005).

students who recognized relationships between different representations demonstrated better conceptual understandings than students who lacked this knowledge (Prain and Waldrip, 2006). In order to achieve better understanding of science concepts, students should be able to translate one representation into another and co-ordinate this knowledge in the process of presenting scientific knowledge (Ainsworth, 1999). According to these theories, submicrorepresentations are only one representational mode in the submicrolevel field of the ITLS model (Devetak et al., 2009).

Research also shows that teachers often explain chemical concepts only at the most abstract level, the symbolic level. Research (Williamson and Abraham, 1995; Georgiadou and Tsaparlis, 2000; Treagust et al., 2001; Wu et al., 2001; Bunce and Gabel, 2002; Papageorgiou and Johnson, 2005; Tien et al., 2007) shows that teachers do not combine macroscopic and submicroscopic levels with the symbolic. Using submicrorepresentations, chemical phenomena could be represented either by stationary illustrations or computer animated interactions between particles. These illustrations can show qualitative or quantitative relations between substances in the chemical phenomena (Devetak and Glažar, 2001). It has been shown (Treagust et al., 2001) that submicrorepresentations are successful only when students are capable of applying their macroscopic chemistry knowledge to the submicroscopic level. Stains and Talanquer (2008) emphasised that the nature of the representations also influenced students' reasoning during solving problems containing submicrorepresentations. The more familiar representations of chemical reactions in symbolic form seemed to trigger the recognition of a larger number of chemically meaningful features, whereas most students struggled in assigning chemical meaning to the submicrorepresentations of chemical reactions. The complexity of and the lack of familiarity with the submicrorepresentations made most students analyze more carefully the nature of the chemical processes that were so represented.

For the learning process, and therefore also for the development of understanding of chemical concepts, the mere combination of all three levels of understanding of chemical concepts is not enough; in these processes intrinsic motivation is crucial (Pintrich and Schunk, 1996; Stipek, 1998; Jarvela,
2001). Students reaching a very high level of intrinsic motivation, who are actively involved in learning tasks, adopt a positive attitude towards the subject and, consequently, those who have a good self-concept for science are also higher achievers in this area. In the literature on educational psychology (Pintrich and Schunk, 1996; Eccles et al., 1998; Stipek, 1998), intrinsic motivation is most frequently described in terms of three interconnected elements the student will have developed by the end of elementary school (age 14): (1) as a special inclination to tackle more demanding tasks that present a challenge; (2) as learning triggered off by curiosity or special interests; (3) as the development of competence and mastering learning tasks in which learning is seen as a value. Research shows that school performance has an impact on future interests and motivation for the selected area of study, as correlations between those variables are statistically significant $(p<0.001)$ (Zusho et al., 2003). Students who are more self-confident at solving difficult or complex problems are more successful at school work, because they apply profound learning strategies leading them towards building up more solid knowledge (Pintrich, 1999). Research results show also the decrease in the interest in science as students progress from lower to upper grades (Anderman and Young, 1994; Zusho et al., 2003), which may be attributed to a number of incorrectly or incompletely understood scientific concepts, as pupils and students do not study science in-depth. In the past such conclusions have led researchers of science education and psychologists to advocate the reform of the science curriculum with varied success. Keig and Rubba (1993) argued that motivation was a potential source of variance in the science test achievements; many students who were not satisfied with their test scores reported in interviews that they had only taken extra science classes because they wanted to enrol at a particular faculty.

Apart from enabling a clearer understanding of concepts, different visualization instruments can stimulate discussion among students about the learning materials, and they can also improve concentration during lessons (Theile and Treagust, 1994, Wu et al., 2001), leading to a higher level of motivation to learn science. Chittleborough and her colleagues (2002) researched motivation to learn chemistry among students in the first year at university level; from interviews they concluded that students were not motivated to learn beyond the boundaries of knowledge necessary to pass the exam. In order to improve the learning motivation in the classroom, Meece and Jones (1996) recommended that teachers should create a learning environment that would: (1) provide learning support for students, (2) monitor students' development, (3) recognise and reward personal development in students' knowledge, and (4) minimize social differences among students. Devetak et al. (2004) found that university students (i.e., pre-service elementary teachers-to-be) were most motivated to learn biology, followed by physics, maths, foreign languages and chemistry. Further, it was also found (Juriševič et al., 2007) that the level of intrinsic motivation was decreasing with subjects with more abstract contents. As regards chemistry, students are highly motivated to learn at the concrete macroscopic level, but less so at the submicro 
and symbolic levels. Most students consider chemistry to be an interesting subject because of the experimental work, which is an important motivator. However, the aim to maintain a high level of motivation with students to learn chemistry at the submicro and symbolic levels of chemical concepts is considered to be very difficult for teachers to achieve (Harrison and Treagust, 2002).

Different types of experimental work (individual and group experimentation, teachers' demonstrations, different types of project work, etc.) constitute the major part in the modernized elementary school science curriculum introduced in the eightyear elementary school. According to the school curriculum reform in Slovenia, the eight-year elementary school (pupils aged from 7 to 14) was replaced by the nine-year elementary school (pupils aged from 6 to 14), which is started at the age of six, i.e. one year earlier than the eight-year elementary school. However, the classification and the level of complexity of science subjects did not change significantly. The students' age on entering the chemistry course was the same (13 years old) as was the number of lessons per week (two 45 minutes lessons). The greatest change was experienced in the curricula of the science subjects, including chemistry, emphasizing active working methods for both teachers and pupils in the nine-year elementary school in contrast to the curricula in the eight-year elementary school which was more lecture-type teaching, where students were less actively involved in the classroom; it was hoped that this would have a positive impact on the motivation of pupils to learn science. Active working methods also enable the linking of experimental results with their interpretations at the submicro level and with symbolic records. The interconnection of three levels when learning chemical concepts should also contribute to gathering information and consequently to the synthesis of knowledge.

To support these new approaches new educational materials were developed for pupils and teachers, and in-service professional development programs were organised for chemistry teachers on how to apply the new teaching methods. Teachers' participation in these in-service training courses was obligatory (3 days - 6 hours per day) for all teachers before they started the new programme in schools. During these in-service training programmes, the teachers pointed out that too frequent activities, which are not carried out in a suitable manner, could have a negative impact on pupils' motivation. With regard to the discussion above, the question can be posed as to the extent to which teachers keep to these methods at chemistry lessons (Glažar, 2005).

\section{Purpose of the research and research question}

The main purpose of this study was to determine the influence of active learning strategies on the pupils' understanding of selected chemical concepts and on their motivation to learn chemistry; these strategies were implemented, according to the reformed curriculum, in the nine-year elementary school (9YP), more frequently than in the eight-year elementary school (8YP) under the previous curriculum.

Accordingly, the main research question is: is there a statistically significant difference between year 8 (old
Table 1 Structure of the Test of Elementary Chemistry Knowledge (TECK)

\begin{tabular}{|c|c|c|}
\hline Topic & $\begin{array}{l}\text { Problem } \\
\text { number }\end{array}$ & $\begin{array}{l}\text { Concepts involved in solving the } \\
\text { problem }\end{array}$ \\
\hline $\begin{array}{l}\text { Pure substances and } \\
\text { mixtures, states of } \\
\text { matter }\end{array}$ & 1,5 & $\begin{array}{l}\text { Atom, molecule, compound, } \\
\text { element, pure substance, mixture, } \\
\text { gas, liquid, solid, particle } \\
\text { arrangement }\end{array}$ \\
\hline $\begin{array}{l}\text { Elements and } \\
\text { compounds }\end{array}$ & 2,6 & $\begin{array}{l}\text { Atom, molecule, compound, } \\
\text { element, particle characteristics }\end{array}$ \\
\hline Chemical reactions & 3,4 & $\begin{array}{l}\text { Atom, molecule, compound, } \\
\text { element, chemical reaction, particle } \\
\text { characteristics }\end{array}$ \\
\hline Electrolyte chemistry* & $7,8,9,10$ & $\begin{array}{l}\text { Aqueous solution, acid, base, salt, } \\
\text { concentration, particle characteristics }\end{array}$ \\
\hline \multicolumn{3}{|c|}{$\begin{array}{l}\text { * - Items analysed for the purposes of this study; see also the Appendix } \\
\text { for items text. }\end{array}$} \\
\hline
\end{tabular}

curriculum) and year 9 (new curriculum) elementary school pupils' achievements in solving the SMR problems dealing with electrolyte chemical concepts and between their intrinsic motivation to learn chemistry?

\section{Hypothesis}

The research question can be divided into four hypotheses:

1. There is a statistically significant difference between the year 8 and year 9 elementary school pupils' achievements at solving submicrorepresentation problems.

2. Year 9 elementary school pupils have similar misconceptions about electrolyte chemistry to those of their year 8 counterparts.

3. Year 9 elementary school pupils are more intrinsically motivated to learn chemistry than their year 8 elementary school counterparts.

4. There is a statistically significant correlation between pupils' intrinsic motivation to learn chemistry, and performance in solving problems at the particulate level and the type of school they attend.

\section{Method}

\section{Participants}

A total of 191 pupils (50.7\% girls, $49.3 \%$ boys) participated in the study, out of whom 110 pupils attended the last (eighth) grade of the eight-year elementary school, whereas 81 pupils attended the last (ninth) grade of the nine-year elementary school. On average they were 13 years and 4 months old. They all had one year of chemistry education prior to participating in this study.

\section{Instruments}

Two instruments were used in this study: Test of Elementary Chemistry Knowledge (TECK) to determine the pupils' basic understanding of specific chemical concepts, and the questionnaire Intrinsic Motivation to Learn Science (IMLS) to determine the pupils' motivation to learn science. Both instruments were developed by the authors.

A paper-and-pencil Test of Elementary Chemistry Knowledge (TECK) comprises ten items on five different topics (Table 1). Pupils had to explain in writing their 
Table 2 Differences in total test score and in the selected items score between eight-year elementary school pupils and nine-year elementary school pupils

\begin{tabular}{|c|c|c|c|c|c|c|}
\hline \multirow{2}{*}{ TECK } & \multirow{2}{*}{ Pupils } & \multirow{2}{*}{$\mathrm{N}$} & \multirow{2}{*}{ M } & \multirow{2}{*}{ SD } & \multicolumn{2}{|c|}{$\mathrm{t}$-test } \\
\hline & & & & & $t$ & $p$ \\
\hline \multirow{2}{*}{ Total test score } & $8 \mathrm{YP}$ & 110 & 9.09 & 3.23 & \multirow{2}{*}{-1.095} & \multirow{2}{*}{0.275} \\
\hline & 9YP & 81 & 9.62 & 3.35 & & \\
\hline \multirow{2}{*}{$\begin{array}{l}\text { Electrolyte } \\
\text { chemistry score }\end{array}$} & $8 \mathrm{YP}$ & 110 & 1.75 & 0.89 & \multirow{2}{*}{1.030} & \multirow{2}{*}{0.305} \\
\hline & 9YP & 81 & 1.60 & 0.98 & & \\
\hline
\end{tabular}

Table 3 Pupils' answers to problem No. 7. The correct submicrorepresentation is in bold

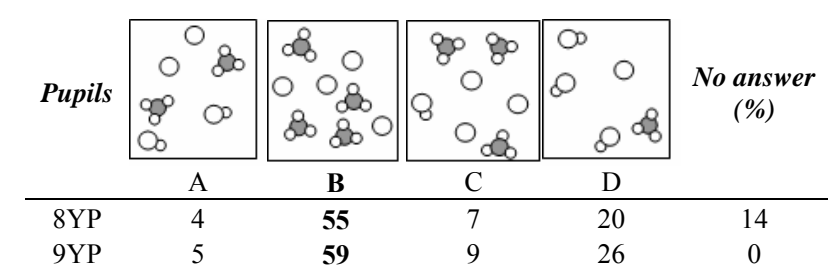

decisions for selecting the specific answers on all items of TECK.

In order to assess the pupils' conceptual understanding of electrolyte chemistry at the particulate levels, four items were used. The TECK showed satisfactory internal consistency (Cronbach $\alpha=0.83$ ). Discriminatory indexes for every item were statistically significant: $p<0.05$. Difficulty indexes were satisfactory.

The 125-item questionnaire Intrinsic Motivation to Learn Science (IMLS) assesses intrinsic motivation to learn biology (IMLS biology), physics (IMLS physics) and chemistry (IMLS chemistry) as well as the general intrinsic motivation to study (IMLS general learning), motivation to learn mathematics (IMLS mathematics) and a foreign language (IMLS foreign language). IMLS's special attention is directed towards the assessment of students' intrinsic motivation to learn chemistry at the three levels of chemical concepts according to the ITLS model (i.e. macro - IMLS macro-, submicro - IMLS submicroand symbolic - IMLS symbolic- level). The items in the IMLS questionnaire measure three components of intrinsic motivation (Pintrich and Schunk, 1996; Stipek, 1998): (1) the emotional component of interest (e.g. I enjoy chemistry classes), (2) the cognitive component of interest (e.g. I am interested in reports about chemistry in the media); (3) the challenge component (e.g. I enjoy the challenge of new chemical problems). The validity of the entire instrument was confirmed by three independent experts in psychology and in science education. The internal consistency (Cronbach $\alpha$ ) of IMLS was between 0.85 and 0.95 for specific parts of the questionnaire.

\section{Data collection and analysis}

The research was a non-experimental, cross-sectional and descriptive study (Bryman, 2004). Both instruments were administered in groups at the end of the chemistry course in the last year of elementary school in accordance with the standard procedures. IMLS and TECK data were analysed using descriptive statistics, Pearson correlation, $t$-test, and chi-square test.

\section{Results}

\section{Test of Elementary Chemistry Knowledge (TECK) results}

Results show (Table 2) that nine-year elementary school pupils (9YP) had an average score only 0.53 points $(3 \%)$ higher than that of their eight-year elementary school (8YP) counterparts. Statistically significant differences in total test score and in the selected items score between 8YP and 9YP were proven by an independent-samples $t$-test. Results show that the difference was not statistically significant $(p>0.05)$. It can be concluded that innovations in the curriculum of the nine-year elementary school and in the methods of teachers' work do not increase pupils' basic understanding of chemical concepts at the submicro level, compared to that of the eightyear elementary school pupils.

\section{Misconceptions of the basic concepts regarding electrolyte chemistry}

Four problems (No 7, No 8, No 9 and No 10) from electrolyte chemistry were selected from the test, because they are very important for understanding the basic characteristics of substances at the macroscopic and submicroscopic levels in the elementary school chemistry (aqueous solutions, concentration, acids, bases, salts). More detailed comparison analysis of achievements and misconceptions was performed to identify possible differences between the eight- and nineyear elementary school pupils' understanding of selected concepts.

\section{Problem No 7}

Pupils had to identify which submicrorepresentation represents an aqueous solution of hydrochloric acid at the particulate level. Water molecules were omitted for reasons of clarity. Pupils had to explain their choice of the submicrorepresentation. They had to understand that hydrochloric acid is a strong acid, causing all its molecules to ionize in the aqueous solution and that only ions (hydroxonium and chloride) are present in aqueous solution in order to solve the problem, which is classified into the application category according to Bloom's cognitive taxonomy.

The results show (Table 3) that 59\% of the 9YP pupils and $55 \%$ of the $8 \mathrm{YP}$ pupils chose the appropriate submicrorepresentation; a chi-square test showed the difference to be not significant $\chi^{2}(1, N=191)=0.252, p=$ 0.616 .

Thus, it can be concluded that more than half of the pupils are familiar with the hydroxonium ion and know that the number of hydroxonium ions and chloride ions in the solution should be the same, as one molecule of hydrochloric acid dissociates into one hydroxonium ion and one chloride ion. Nevertheless, the proportion of pupils who chose D submicroscopic representation is still big, i.e. $20 \%$ of the $8 \mathrm{YP}$ pupils and $26 \%$ of the $9 \mathrm{YP}$ pupils. These pupils do not know 
Table 4 Some students' justifications of submicrorepresentation selection at solving Problem No 7

\begin{tabular}{|c|c|c|}
\hline The level of justification as regards ITLS model & 8YP (f) & 9YP (f) \\
\hline Macro level & 10 & 5 \\
\hline 1. Chlorine will bind with water into hydrochloric acid. & 2 & 1 \\
\hline 2. Hydrogen and chlorine are bound together. & 5 & - \\
\hline 3. Hydrogen and chlorine are mixed. & 3 & - \\
\hline 4. Hydrogen is bound to water. & - & 2 \\
\hline 5. Hydrochloric acid contains chlorine and water. & - & 1 \\
\hline 6. Most of the chlorine. & - & 1 \\
\hline Submicro level & 6* & 5 \\
\hline 1. Because there is only one water molecule. & 2 & - \\
\hline 2. Chloride ions are alone, on other schemes other ions are attached to them. & - & 1 \\
\hline 3. Three atoms of hydrogen are bound to one atom of oxygen. & - & 1 \\
\hline 4. The same number of chlorine and hydrogen atoms. & - & 1 \\
\hline 5. Particles are mixed. & - & 1 \\
\hline 6. Some chloride ions and some water molecules. & - & 1 \\
\hline Macro- submicro level & $4 *$ & 7 \\
\hline 1. Water is bound to every chlorine atom. & - & 3 \\
\hline $\begin{array}{l}\text { 2. In water the acid gives away atoms of hydrogen, out of which hydroxonium ions are produced. No atom of hydrogen is } \\
\text { bound to the compound. }\end{array}$ & - & 1 \\
\hline 3. In aqueous solutions acids decompose into the hydroxonium ion and acidic residue. & - & 2 \\
\hline 4. The solution produces atoms. & 2 & - \\
\hline 5. Chlorine is not bound to the hydroxonium ion or to hydrogen. & - & 1 \\
\hline Macro- submicro- symbolic level & 1 & 3 \\
\hline 1. The acid decomposes in water into $\mathrm{Cl}^{-}$ion, $\mathrm{H}_{3} \mathrm{O}^{+}$and $\mathrm{H}_{2} \mathrm{O}$. & 1 & 1 \\
\hline 2. $\mathrm{H}_{2} \mathrm{O}+\mathrm{HCl} \longrightarrow \mathrm{H}_{3} \mathrm{O}^{+}+\mathrm{Cl}^{-}$water reacts with hydrogen out of the acid producing hydroxonium ion and chloride. & - & 1 \\
\hline 3. Because there is one $1 \mathrm{H} \rightarrow \mathrm{HCl}$ in the acid, which is bound to water producing $\mathrm{H}_{3} \mathrm{O}^{+}$and only $\mathrm{Cl}^{-}$remains. & - & 1 \\
\hline
\end{tabular}

* - frequencies for the eight-year school are not the sums of the specific examples of justifications presented in the subcategories, because those justifications that appeared only once were not included in the Table.

Table 5. Pupils' answers to problem No 8. The correct submicrorepresentation is in bold

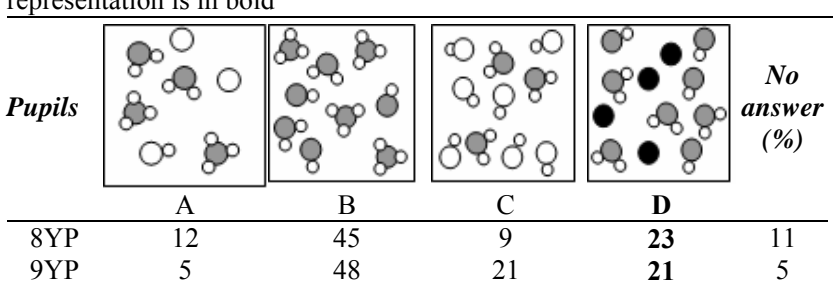

that hydrochloric acid is a strong acid, as the scheme comprises three quarters of the drawn molecule particles which did not ionize. All the 9YP pupils answered the question but $14 \%$ of the 8 YP pupils did not. Perhaps they had less confidence in the accuracy of the answers provided, so they preferred not to respond at all.

Table 4 shows that only 41 of the pupils $(21.5 \%)$ in total gave reasons for their responses, the share of justifications among the 8YP pupils (19.1\%) being somewhat lower than among the 9YP pupils $(24.4 \%)$, with no significant difference in the justification modes. The majority of the pupils justified their submicroscopic representation selection at the macroscopic level, of which most of the pupils only described submicroscopic representation as their choice, e.g. hydrogen and chlorine are bound. The second most common justification from nine-year elementary school pupils was a combination of the macroscopic and submicroscopic levels of concepts. Fewer pupils justified their selection of submicroscopic representation only with the submicroscopic level, with the combination of the macro-and symbolic levels or with the combination of all three levels. The differences in the number of justifications between eight-year and nine-year school is not significant.

\section{Problem No 8}

In this task the pupils had to choose a submicroscopic representation showing a basic aqueous solution and justify their choice. The task is classified into the cognitive comprehension category according to Bloom, as pupils should be familiar with hydroxide ions to provide the correct answer.

As Table 5 shows, on average, only $22 \%$ of the pupils provided the correct answer, which means that less than one quarter of the pupils knows that hydroxide ions cause the basic characteristics of aqueous solutions. A chi-square test for independence showed no significant difference between the proportion of correct answers from the two groups, $\chi^{2}(1$, $N=191)=0.066, p=0.797$. Only $23.2 \%$ of the 9YP pupils justified their answers and only $12.7 \%$ of the $8 \mathrm{YP}$ pupils, did so (Table 6).

The analysis of the justifications of the submicroscopic representation selection at task No 8 shows that the majority of the pupils justified their selection with the combination of the macroscopic and submicroscopic levels of chemical concepts. The majority of the responses gave the reasons that a base decomposes or ionizes in water into the hydroxide ion, and that in the aqueous basic solution there are also hydroxonium ions present. This explanation occurs in the new program only once. More 9YP pupils tried to explain the phenomena on submicro level than did their 8 YP counterparts.

\section{Problem No 9}

In order to be successful at this task, pupils had to choose the most concentrated solution among five submicroscopic 
Table 6 Students' justifications of their submicrorepresentation selections at problem No 8

\begin{tabular}{|c|c|c|}
\hline The justification level as regards ITLS model & $\begin{array}{l}8 Y P \\
(f)\end{array}$ & $\begin{array}{l}9 Y P \\
(f)\end{array}$ \\
\hline Macro level & $\mathbf{0}$ & 2 \\
\hline 1. More water. & - & 1 \\
\hline $\begin{array}{l}\text { 2. Because they are bound together, therefore } \mathrm{C} \text { is the } \\
\text { right answer. }\end{array}$ & - & 1 \\
\hline Submicro level & 1 & 6 \\
\hline 1. More hydroxide ions & - & 2 \\
\hline 2. Most of the water molecules. & - & 2 \\
\hline 3. Hydroxonium ions. & 1 & 1 \\
\hline 4. There is no hydroxonium ion. & - & 1 \\
\hline Macro- submicro level & 13 & 9 \\
\hline $\begin{array}{l}\text { 1. Beside the water molecules some hydroxide ions are } \\
\text { drawn, which are significant for bases. }\end{array}$ & 1 & 1 \\
\hline $\begin{array}{l}\text { 2. Atoms containing two hydrogens will give one away, } \\
\text { and hydroxide ions will be produced. }\end{array}$ & - & 1 \\
\hline $\begin{array}{l}\text { 3. In water a base decomposes into some element, } \\
\text { hydroxide ion and water. }\end{array}$ & - & 3 \\
\hline $\begin{array}{l}\text { 4. Aqueous solution contains water molecules, hydroxide } \\
\text { ions and hydroxonium ions. }\end{array}$ & 6 & 1 \\
\hline $\begin{array}{l}\text { 5. Hydroxide ions and some other element are significant } \\
\text { for bases. }\end{array}$ & - & 1 \\
\hline $\begin{array}{l}\text { 6. In aqueous solution a base decomposes into hydroxide } \\
\text { ion. }\end{array}$ & 4 & 2 \\
\hline 7. A base takes away atoms out of aqueous solution. & 2 & - \\
\hline Macro- symbolic level & $\mathbf{0}$ & 2 \\
\hline $\begin{array}{l}\text { 1. } \mathrm{OH}^{-} \text {is only in } \mathrm{D} \text { a molecule of hydroxide ion. } \\
\text { 2. During the water - base reaction hydroxide ion } \mathrm{OH}^{-} \text {is }\end{array}$ & - & 1 \\
\hline $\begin{array}{l}\text { separated from the base. Hydroxide ion is not } \\
\text { produced. In the legend oxygen is not white, but grey. }\end{array}$ & - & 1 \\
\hline
\end{tabular}

Table 7 Pupils' answers to problem No 9. The correct submicrorepresentation is in bold

\begin{tabular}{|c|c|c|c|c|c|c|}
\hline \multirow{3}{*}{ Pupils } & 00 & $\circ \circ$ & 0 & & & \multirow{3}{*}{$\begin{array}{l}\text { No } \\
\text { answer } \\
(\%)\end{array}$} \\
\hline & 0 & 0 ०० & 00 & $0_{0}^{\circ} \mathrm{O}$ & $\circ \circ 0$ & \\
\hline & A & B & $\mathrm{C}$ & D & E & \\
\hline $8 \mathrm{YP}$ & 3 & 19 & 5 & 66 & 0 & 6 \\
\hline 9YP & 0 & 24 & 4 & 64 & 7 & 1 \\
\hline
\end{tabular}

representations of aqueous solutions of the same substance. The pupils had to justify their selection. In order to solve this task they had to be familiar with the chemical concepts of solution and concentration. The task is classified into the third cognitive application category according to Bloom. In order to solve the problem two criteria had to be connected: the number of the solute particles and the volume of the solution, as both criteria were changing in the submicroscopic representations of the task. The problem was selected because the concept of solution concentration is very important according to the elementary school curriculum, and the appropriate way for evaluating students' understanding is by taking into account the volume of the solution (macro level) and particle numbers (submicro level). Without the volume the concept of concentration would be meaningless.

The results (Table 7) show that pupils experienced no major difficulties at this task. The appropriate submicroscopic representation was selected by $66 \%$ of the $8 \mathrm{YP}$ and $64 \%$ of

Table 8 Students' justifications of submicrorepresentation selection at solving problem No 9

\begin{tabular}{lcc} 
& $8 Y P$ & $9 Y P$ \\
The justification level as regards ITLS model & (f) & (f) \\
\hline $\begin{array}{l}\text { Macro level } \\
\text { 1. The liquid amount is smaller, therefore the concentration } \\
\text { is greater. }\end{array}$ & 8 & 5 \\
2. The greatest concentration per amount of water. & - & 2 \\
3. The least of solvent and most of solute. & 2 & 6 \\
4. The least of water and a lot of some substance (small & 20 & 16 \\
circles, small dots, elements). & 1 & 1 \\
5. Four small circles in 250 mL of water. & - & 1 \\
6. Because circles are arranged throughout the entire & - & $\mathbf{3}$ \\
$\quad$ container. & - & 3 \\
$\begin{array}{l}\text { Submicro level } \\
\text { 1. The most molecules (atoms) }\end{array}$ & $\mathbf{1 0 *}$ & $\mathbf{1 0}$ \\
Macro- submicro level & 8 & 10 \\
1. The most atoms per amount of water. & &
\end{tabular}

the 9YP pupils; a chi-square test showed no significant difference between the answers of the two groups, $\chi^{2}(1$, $N=191)=0.001, p=0.979$. The majority of the pupils chose B as the wrong answer $(24 \%$ of the $9 \mathrm{YP}$ pupils and $19 \%$ of the $8 Y \mathrm{P}$ pupils). Submicroscopic representation B shows most particles; however, the volume also has to be taken into account, which these pupils failed to do.

The majority of the pupils presented their justifications only at the macroscopic level (Table 8 ). $20 \%$ of the $8 \mathrm{YP}$ pupils as well as $22 \%$ of the 9YP pupils simply justified their responses by just counting the numbers of 'small dots or circles' or similar expressions in a certain amount of the solvent. Fewer pupils gave reasons for their responses using the submicroscopic level of chemical concepts and the combination of macroscopic and submicroscopic levels, respectively. From the pupils' explanations it can be concluded that the macroscopic element in the submicrorepresentation can influence their explanations at the macro level. Altogether, all explanations - even those that show some submicro elements - were at the macro level in eight-year programme, and less than $7 \%$ of all justifications from 9YP pupils were only at the submicro level. As many as 105 pupils (55\%) did not offer any explanation for their responses.

\section{Problem No 10}

The pupils had to choose out of five submicroscopic representations the one showing the appropriate arrangement of particles in an aqueous solution of sodium chloride. In submicroscopic representations water molecules were omitted in order to ensure clarity. The pupils also had to take into account that sodium chloride dissolves well in water; further, that it is an ionic solution, which means that in aqueous solution sodium and chloride ions are to be found among the water molecules. Their selections had to be justified by the pupils. To solve this problem the pupils had to be familiar with the following chemical concepts: ion, ionic compound, aqueous solutions of ionic compounds. The task is classified into the cognitive application category according to Bloom, as pupils had to choose the suitable submicroscopic 
Table 9 Pupils' answers to problem No 10. The correct submicrorepresentation is in bold

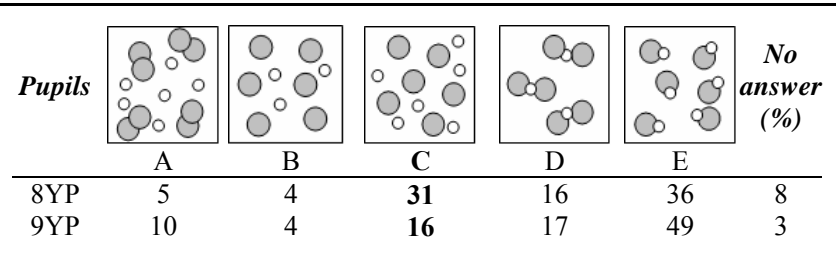

Table 10 Students' justifications of their submicrorepresentation selection in problem No 10

\begin{tabular}{lcc}
$\begin{array}{l}\text { The justification level as regards ITLS model } \\
\text { Macro level }\end{array}$ & $\begin{array}{c}8 Y \mathrm{P} \\
\text { (f) }\end{array}$ & $\begin{array}{c}9 \text { YP } \\
\text { (f) }\end{array}$ \\
1. Because chlorine and sodium are bound. & $\mathbf{6}$ & $\mathbf{5}$ \\
2. Because no element is attached. & 1 & 4 \\
Macro- submicro level & 5 & 1 \\
1. Cations and anions are separated in water; the & $\mathbf{6}$ & $\mathbf{7}$ \\
proportion is 1:1. & - & 1 \\
2. Sodium gives away 1 electron, whereas chlorine & & \\
receives 1 electron, therefore they are joined. & - & 1 \\
3. Sodium chloride, atoms are separated in water. & 3 & - \\
4. There are no molecules in the solution. & - & 2 \\
5. Two atoms of chlorine and one atom of sodium. & 3 & 2 \\
6. Chlorine enters into the reaction as a molecule, whereas & - & 1 \\
$\quad$ sodium as an element. & $\mathbf{0}$ & $\mathbf{2}$ \\
Macro- symbolic level & - & 1 \\
1. NaCl decomposes in water. & - & 1 \\
2. Salts decompose into Na ${ }^{+}$and Cl ${ }^{-}$. & $\mathbf{1 3}$ & $\mathbf{5}$ \\
Submicro level & - & 1 \\
1. Two chloride ions are bound to each sodium atom. & 1 & 1 \\
2. There are no ions elsewhere, as one has to count & 2 & 1 \\
particles. & 8 & 2 \\
3. Every chlorine atom has its sodium atom. & 2 & - \\
4. Six chloride and six sodium ions, which are bound & $\mathbf{1}$ & $\mathbf{4}$ \\
together. & 1 & 4 \\
5. Chloride and sodium ions are bound together. & $\mathbf{2 6}$ & $\mathbf{2 3}$ \\
Submicro- symbolic level & & \\
1. NaCl is composed of sodium and chloride ions. & Total: & \\
\hline
\end{tabular}

Table 11 The difference between pupils' intrinsic motivation to learn chemistry in $8 \mathrm{YP}$ and 9YP

\begin{tabular}{|c|c|c|c|c|c|}
\hline \multirow{2}{*}{ Intrinsic motivation } & \multirow{2}{*}{ Pupils } & \multirow{2}{*}{$\mathrm{M}$} & \multirow{2}{*}{$S D$} & \multicolumn{2}{|c|}{$t$-test } \\
\hline & & & & $t$ & $p$ \\
\hline \multirow{2}{*}{ IMLS chemistry } & $8 Y \mathrm{YP}$ & 46.47 & 10.05 & \multirow{2}{*}{4.045} & \multirow{2}{*}{0.000} \\
\hline & $9 \mathrm{YP}$ & 39.93 & 12.29 & & \\
\hline \multirow{2}{*}{ IMLS macro } & $8 \mathrm{YP}$ & 53.14 & 9.49 & \multirow{2}{*}{2.074} & \multirow{2}{*}{0.039} \\
\hline & 9YP & 50.09 & 10.75 & & \\
\hline \multirow{2}{*}{ IMLS submicro } & $8 Y \mathrm{Y}$ & 41.24 & 11.42 & \multirow{2}{*}{1.117} & \multirow{2}{*}{0.266} \\
\hline & 9YP & 39.38 & 11.28 & & \\
\hline \multirow{2}{*}{ IMLS symbolic } & $8 Y \mathrm{YP}$ & 40.80 & 11.34 & \multirow{2}{*}{1.833} & \multirow{2}{*}{0.068} \\
\hline & 9YP & 37.68 & 12.01 & & \\
\hline
\end{tabular}

representation on the basis of their knowledge on aqueous solutions of ionic compounds.

It is surprising that the proportion (Table 9; bold text) of nine-year school pupils who answered the problem correctly was significantly lower than the proportion of eight-year school pupils who selected the correct submicrorepresentation, $\chi^{2}(1, N=191)=4.78, p=0.029$.
Almost half of the 9YP pupils and over a third of the $8 \mathrm{YP}$ pupils decided on the $\mathrm{E}$ submicroscopic representation in which the sodium chloride molecules in aqueous solution are wrongly presented, so they know that the proportion between sodium and chlorine in sodium chloride is $1: 1$, but they do not know that an aqueous solution contains sodium ions and chloride ions. Approximately $17 \%$ of all the pupils are not familiar with the sodium chloride composition, which is most often used as an example when explaining an ionic bond.

In total, $24.5 \%$ of the $8 \mathrm{YP}$ pupils and $28 \%$ of the $9 \mathrm{YP}$ pupils tried to justify their responses (Table 10); the majority of the pupils used the macroscopic level in justifying their choice of the submicroscopic representation, which was most often wrongly described. The pupils using the submicro level or a combination of macro- and submicro levels to justify their responses were also trying to give reasons for their choices by describing particles in the aqueous solution of sodium chloride. It can be summarised again from Table 10, that there were more explanations at the submicro level in eight-year than in nine-year elementary school. This may indicate that the new curriculum does not lead to pupils' deeper understanding of the submicrolevel. Similarly to previous tasks, the majority of the pupils $(73.8 \%)$ did not give reasons for their responses.

\section{Intrinsic motivation and chemistry learning}

Table 11 shows that 8 YP pupils are more motivated than 9YP pupils for all the levels of chemical concepts. 8YP pupils were statistically significantly more motivated to introduce and observe chemical changes (macroscopic level) than 9YP pupils, and they were also more motivated to learn chemistry $(p \leq 0.000)$.

The differences in motivation for the submicro level and the symbolic level are not statistically significant. Pupils find the macroscopic level to be closest to their perception, most interesting and understandable. The biggest drop in motivation was noticed at changing over to the submicro level, whereby pupils should develop mindsets for the world of particles, which they perceive as the most abstract one. The transfer from the concrete to the abstract level caused an average drop in intrinsic motivation by as many as 11.4 points in pupils. The transfer from the submicro- to the symbolic level is easier for the pupils, yet the level of motivation decreases only by 0.97 points on average. Thus, the new curriculum did not contribute to an increase of interest in chemistry, and teachers probably neither apply methods nor perform activities through the new curriculum that would be very different from those applied in the $8 \mathrm{YP}$ school. These results also confirm the results obtained from Table 2, which do not show significant differences in understanding chemical concepts at the level of particles between the 8YP pupils and $9 Y \mathrm{P}$ pupils. On the basis of these results it would be recommended for teachers to introduce such working methods and activities that would encourage the pupils' external motivation, which would later on be turned into internal motivation for understanding chemical concepts and rules based on positive experiences. Students can be extrinsically motivated for chemistry learning in such educational 
Table 12 Correlations between pupils' intrinsic motivation to learn chemistry and performance at electrolyte chemistry items

\begin{tabular}{lcccc}
\hline & $\begin{array}{c}\text { IMLS } \\
\text { chemistry }\end{array}$ & $\begin{array}{c}\text { IMLS } \\
\text { macro }\end{array}$ & $\begin{array}{c}\text { IMLS } \\
\text { submicro }\end{array}$ & $\begin{array}{c}\text { IMLS } \\
\text { symbolic }\end{array}$ \\
\hline $\begin{array}{l}\text { 8YP electrolyte } \\
\text { achievement score }\end{array}$ & 0.065 & $0.221^{*}$ & 0.050 & 0.032 \\
$\begin{array}{l}\text { 9YP electrolyte } \\
\text { achievement score }\end{array}$ & $0.301^{*}$ & 0.198 & $0.283^{*}$ & $0.320^{*}$ \\
$* 0.05$. & & & & \\
\hline
\end{tabular}

situations that can see the relevance of chemical concepts. This relevance can be obtained by introducing concepts through contexts familiar and interesting to the students (i.e. forensic chemistry, food chemistry, sport science, science in the media). Active learning approaches can also be extrinsically oriented strategies for stimulating students' interest in chemistry. This means that students should learn actively (by reading, reflecting, discussing, analysing, evaluating and drawing conclusions) in a social context (group work).

All correlations between pupils' performance at the total test score and intrinsic motivation to learn chemistry regardless of the type of schooling were statistically insignificant and low. On the other hand, the correlations between pupils' performance at items including electrolyte chemistry and intrinsic motivation to learn chemistry were significant in some cases, but still low (see Table 12). Chemistry-in-context and more active educational strategies, as proposed to the teachers by the reformed chemistry curriculum (9YP), may influence students' achievements when solving electrolyte chemistry problems more than in the old curriculum. From this point of view the new curriculum may contribute to students' higher motivation for learning even more abstract ideas as electrolyte chemistry concepts indubitably are.

\section{Conclusions and implications for education}

Based on the results, it can be concluded that on average the performance of the 9YP pupils was slightly better (by 3\%) than the performance of the $8 \mathrm{YP}$ pupils, but the difference is not statistically significant, so the first hypothesis can not be confirmed.

Similar conclusions can be made for the selected tasks from the field of aqueous solutions of electrolytes, as the $8 \mathrm{YP}$ pupils were more successful at solving the selected problems, but the difference is not statistically significant. According to these results the second hypothesis can not be confirmed.

With a more detailed analysis of responses it can be established that on average, only $57 \%$ of the respondents understand that strong acids almost completely decompose into ions in aqueous solutions. The rest of the pupils are not able to connect the abstract concept of the strength of acid with the concrete example of a strong acid, as set in the task.

On average as many as $78 \%$ of the pupils don't know the particles in basic aqueous solutions. Thus, pupils (an average of $46.5 \%$ ) believe that, apart from hydroxide ions, aqueous solutions also contain considerable amounts of hydroxonium ions.
The findings of the study also show that almost two thirds of the respondents of both groups understand the concept of the solution concentration. Among the wrong responses, the majority of the pupils (an average of $21.5 \%$ ) chose the wrong submicroscopic representation, as they did not take into account the volume of the solution when deciding on the solution concentration, but only the number of the particles of the solute. On the basis of the analysis of the wrong responses to the task dealing with the sodium chloride composition, it can be concluded that almost half of the 9YP pupils believe that the aqueous solution contains sodium chloride molecules, in which sodium and chlorine atoms are bound in $1: 1$ proportion. Similar misconceptions are also observed with secondary school students (Devetak, 2005) and university students (Šegedin, 2001; Devetak et al., 2004). However, attention should also be paid to the fact that on average as many as $72.2 \%$ of the pupils did not justify their responses. This is probably due to the fact that at multiple choice tasks in school tests students are not used to having to justify their answers. If they did, they would learn to express themselves in a scientific manner, and the teacher would gain useful information on their understanding of the subject matter, which is not always possible to conjecture from their selected answers.

The justifications show pupils' inability to express themselves precisely. They do not provide answers in terms of particles, i.e. atoms, ions and molecules of substances, but at the macroscopic level when they state the names of substances.

\section{Appendix}

\section{Problem No 7}

Which scheme represents an aqueous solution of hydrochloric acid at the particulate level? Water molecules were omitted for clarity.

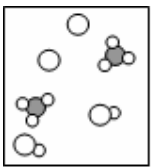

A

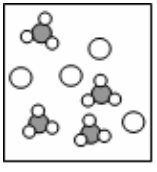

B

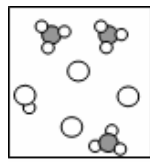

$\mathrm{C}$
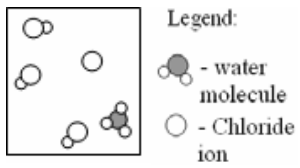

ion

$\mathrm{D}$
Explain your choice:

\section{Problem No 8}

Which scheme represents an aqueous solution of a base? Water molecules were omitted for clarity.
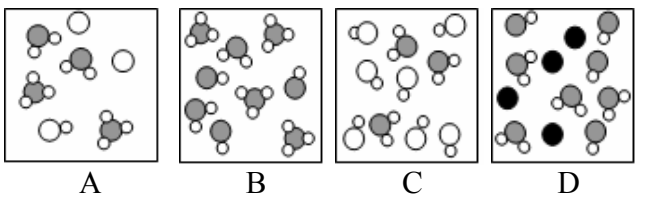

Legend:

- water molecule - Chloride ion

Explain your choice: 


\section{Problem No 9}

Which scheme (from A to E) represents an aqueous solution of the same substance with the greatest concentration? Water molecules were omitted for clarity.

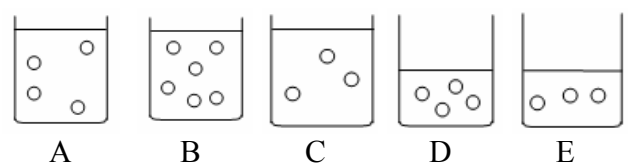

Explain your choice:

\section{Problem No 10}

Which scheme represents an aqueous solution of sodium chloride? Water molecules were omitted for clarity.

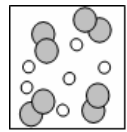

A

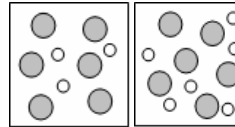

B

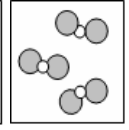

$\mathrm{C}$

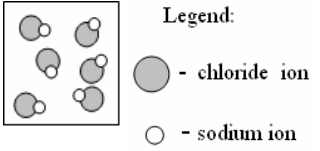

E
Explain your choice:

\section{References}

Ainsworth S., (1999), The functions of multiple representations, Comput. Educ., 33, 131-152.

Anderman E. M. and Young A. J., (1994), Motivation and strategy use in science: individual differences and classroom effects, J. Res. Sci. Teach. , 31, 811-831.

Bradley J. D., Brand M. and Gerrans G. G., (1998), Stages of development in student's concepts about macroscopic properties and microscopic structure of matter: an analysis of data from South African secondary schools, S. Afr. J. Chem., 51, 85-93.

Bryman A., (2004), Social research methods, Oxford University Press, New York.

Bunce D. M. and Gabel D., (2002), Differential effects in the achievement of males and females of teaching the particulate nature of chemistry, J. Res. Sci. Teach., 39, 911-972.

Chittleborough G. D., Treagust D. F. and Mocerino M., (2002), Constraints to the development of first year university students mental models of chemical phenomena, Teaching and Learning Forum 2002: focusing on the student, retrieved January 30, 2004, from http://otl.curtin.edu.au/tlf/tlf2002/abstracts/chittleboroughabs.html.

Devetak I., (2005), Explaining the latent structure of understanding submicropresentations in science, Doctoral Dissertation, University of Ljubljana, Ljubljana.

Devetak I. and Glažar S. A., (2001), Implementation of submicrorepresentations for evaluating chemical knowledge, (in Slovenian) P. Glavič, D. Brodnjak-Vončina (eds.), Proceedings from symposium, Slovenia Chemical Event 2001, Faculty of chemistry and chemical technology, Maribor, 1002-1009, pp. 1002-1009.

Devetak I., Urbančič M., Wissiak-Grm K. S., Krnel D. and Glažar S. A., (2004), Submicroscopic representations as a tool for evaluating students' chemical conceptions, Acta Chim. Slov., , 51, 799-814.

Devetak I., Vogrinc J. and Glažar S. A., (2009), Assessing 16-year-old students' understanding of aqueous solution at submicroscopic level, Res. Sci. Educ., 39, 157-179.
Eccles J. S., Wigfield A. and Schiefele U., (1998), Motivation to succeed. in: W. Damon, and N. Eisenberg (eds.) Handbook of child psychology, Vol. 3, John Wiley and Sons, New York, pp. 1017-1095.

Gabel D., (1999), Improving teaching and learning through chemistry evaluation research: a look to the future, J. Chem. Educ., 76, 548554.

Georgiadou A. and Tsaparlis G., (2000), Chemistry teaching in lower secondary school with methods based on: a) psychological theories; b) the macro, representational, and submicro levels of chemistry, Chem. Educ. Res. Pract., 1, 217-226.

Glažar S. A., (2005), The influence of assessment on pupils' knowledge and their interest for science learning: implementation of a new curriculum for 7th grade science: an evaluation study (in Slovenian). Faculty of Education, Ljubljana.

Harrison A. G. and Treagust D. F., (2002), The particulate nature of matter: challenges in understanding the submicroscopic world, in: J. K. Gilbert (ed.), Chemistry Education: Towards Research - Based Practice, Kluwer Academic Publishers, Netherlands, 189-212.

Jarvela S., (2001), Shifting research on motivation and cognition to an integrated approach on learning and motivation in context, in: V. Jarvela (ed.), Motivation in learning context: theoretical advances and methodological implications, Pergamon, Amsterdam, 3-14.

Johnstone A. H., Sleet R. J. and Vianna J. F., (1994), An information processing model of learning: its application to an undergraduate laboratory course in chemistry. Stud. High. Educ., 19, 77-87.

Johnson P., (1998), Children's understanding of changes of state involving the gas state, Part II: evaporation and condensation below boiling point, Int. J. Sci. Educ. , 20, 695-709.

Juriševič M., Devetak I., Razdevšek-Pučko C. and Glažar S. A., (2008), Intrinsic motivation of pre-service primary school teachers for learning chemistry in relation to their academic achievement, Int. J. Sci. Educ., 30, 87-107.

Juriševič M., Vogrinc J., Glažar S. A. and Devetak I., (2007), Intrinsic motivation for learning chemistry in Slovenian primary, secondary and university level schools, in: ESERA 2007, European Science Education Research Association, Malmö University, Malmö, p. 4.

Keig P. F. and Rubba P. A., (1993), Translation of representations of structure of matter and its relationship to reasoning, gender, spatial reasoning, and specific prior knowledge, J. Res. Sci. Teach., 30, 883903.

Lemke J., (2004), The literacies of science, in: E. W. Saul (ed.), Crossing borders in literacy and science instruction: perspectives on theory and practice, International Reading Association / National Science Teachers Association Arlington, 33-47.

Mayer R. E., (1993), Illustrations that instruct, in: R. Glaser (ed.), Advances in instructional psychology, Lawrence Erlbaum Associates, Hillsdale, pp. 253-284.

Mayer R. E., (1996), Learning strategies for making sense out of expository text: The SOI model for guiding three cognitive processes in knowledge construction, Educ. Psychol. Rev., 8, 357-371

Mayer R. E. and Moreno R., (2001), A cognitive theory of multimedia learning: implications for design principles, retrieved June 30, 2007, from http://www.unm.edu/ moreno/PDFS/chi.pdf.

Meece J. L. and Jones M. G., (1996), Gender differences in motivation and strategy use in science: are girls rote learners?, J. Res. Sci. Teach., 33, 393-406.

Papageorgiou G. and Johnson P., (2005), Do particle ideas help or hinder pupils' understanding of phenomena?, Int. J. Sci. Educ., 27, 12991317.

Paivio, A. (1986). Mental representations: a dual coding approach. Oxford University Press, New York.

Prain V. and Waldrip B., (2006), An exploratory study of teachers' and students' use of multi-modal representations of concepts in primary science, Int. J. Sci. Educ., 28, 1843-1866.

Pintrich P. R. and Schunk D. H., (1996), Motivation in education: theory, research, and applications, Englewood Cliffs, Prentice Hall, New Jersey.

Pintrich P. R., (1999), The role of motivation in promoting and sustaining self-regulated learning, Int. J. Sci. Educ., 31, 459-470. 
Sanger M. J., (2000), Using particulate drawings to determine and improve students' conceptions of pure substances and mixtures, $J$. Chem. Educ., 77, 762-766.

Šegedin P., (2001), Students' understanding of physical and chemical change (in Slovenian), Chem. School, 13, 2-5.

Solsona N., Izquirdo M. and deJong O., (2003), Exploring the development of students' conceptual profiles of chemical change, Int. J. Sci. Educ. , 25, 3-12.

Stains M. and Talanquer V., (2008), Classification of chemical reactions: stages of expertise, J. Res. Sci. Teach., 45, 771-793.

Stipek D., (1998), Motivation to learn: from theory to practice, Allyn and Bacon, Boston.

Thiele R. B. and Treagust D. F., (1994), An interpretative explanation of high school chemistry teachers' analogical explanations, J. Res. Sci. Teach. , 31, 227-242.

Tien L. T., Teichert M. A. and Rickey D., (2007), Effectiveness of a MORE laboratory module in prompting students to revise their molecular-level ideas about solutions, J. Chem. Educ., 84, 175-180.
Toth Z. and Kiss E., (2006), Using particulate drawings to study 13-17 year olds' understanding of physical and chemical composition of matter as well as the state of matter, Pract. The. Sys. Educ., 1, 109 125, retrieved April 4, 2009, from http:/leduscience.fw. hu.

Treagust D. F., Chittleborough G. D. and Mamiala T. L., (2001), The function of macroscopic, symbolic and sub-microscopic representations in explaining concepts in high school chemistry, Sci. Teach. Learn., retrieved January 30, 2004, from $\mathrm{http} / /$ tigersystem.net/aera2002/view proposaltext. asp?proplD=5854.

Williamson V. M. and Abraham M. R., (1665), The effects of computer animation on the particulate mental models of college chemistry students, J. Res. Sci. Teach., 32, 521-534.

Wu H.-K., Krajcik J. S. and Soloway E., (2001), Promoting understanding of chemical representations: students' use of a visualisation tool in the classroom, J. Res. Sci. Teach. ,38, 821-842.

Zusho A., Pintrich P. R. and Coppola B., (2003), Skill and will: the role of motivation and cognition in the learning of college chemistry, Int. J. Sci. Educ., 25, 1081-1094. 